\title{
Analysis and Prevention of Tubeburst in Rear Platen Superheater of Boiler
}

\author{
Ke LIU ${ }^{1, \text { a }}$, Hui LIU ${ }^{2}$, Fanjun $\mathrm{HOU}^{1}$ \\ ${ }^{1}$ State Grid Shandong Electric Power Research Institute, Jinan 250003,China; \\ ${ }^{2}$ Datang Lubei Power Generation Co.,Ltd, Binzhou 251909, China. \\ aluliuke@163.com
}

Keywords: Boiler; Water blocking; Rear platen superheater

\begin{abstract}
Tube burst occurred on Rear Platen Superheater in No.4 boiler of a power plant. Failed to timely discharge condensate water after an emergency shutdown boiler, and then start again, which leading to water blocking in superheater unit caused tube burst. Contrasting the water blocking accidents recent years in this boiler, corresponding preventive measures are formulated, which have certain reference value to theproblems of tubeburst caused by water blocking of the same type boiler.
\end{abstract}

\section{Introduction}

Boiler tube explosion is a major problem affecting the safe operation of power plants. Some analyses have pointed out that most of these tube explosions occur in the same pipe, the same material or the same area of the boiler repeatedly, indicating that the root cause of the failure has not been determined [1-2]. The factors causing the tube explosions are complicated, and the water plug is a common factor. The so-called water plug means that during the starting process of the boiler, due to various reasons, there is water accumulated in the vertical convection superheater, causing the steam cannot go through the heating tube smoothly. Then there is dry burning in the heating tube and the short-term overheat causes the explosion [3-5].

\section{Equipment overview}

A power plant Unit 4 was put into production in 2008. It is equipped with the boiler produced by Shanghai Boiler Works Co., Ltd. It is the Model SG-1025/17.5-M881 subcritical drum boiler to control the cycle. Single furnace with one middle reheat, the boiler takes a layout for outdoor arrangement with solid slag. The maximum continuous evaporation of the boiler is $1,025 \mathrm{t} / \mathrm{h}$. The boiler uses the tangential combustion by the swing-type single furnace DC burner which is four-corner arranged. And the boiler uses five medium-speed pulverizers with the direct-fired powder feeding system.

The superheater system consists of five grades, namely, the top and the steam-coated tube, the low-temperature superheater (the primary desuperheater), the divided platen, the rear panel, the secondary desuperheater, the final superheater, as shown in Figure 1. The rear panel superheater is arranged behind the divided platen with a total of 20 pieces. Each piece is composed of 14 parallel tubes, as shown in Figure 2. The outer diameter of the outermost heating tube is $60 \mathrm{~mm}$. The outer diameter of other inner tubes is $54 \mathrm{~mm}$ and the transverse pitch is $684 \mathrm{~mm}$. The bottoms of the outermost three circles and the innermost wound tube use the stainless steel, and the rest uses 12Cr1MoV, SA213-T91, 15CrMo alloy steel. 


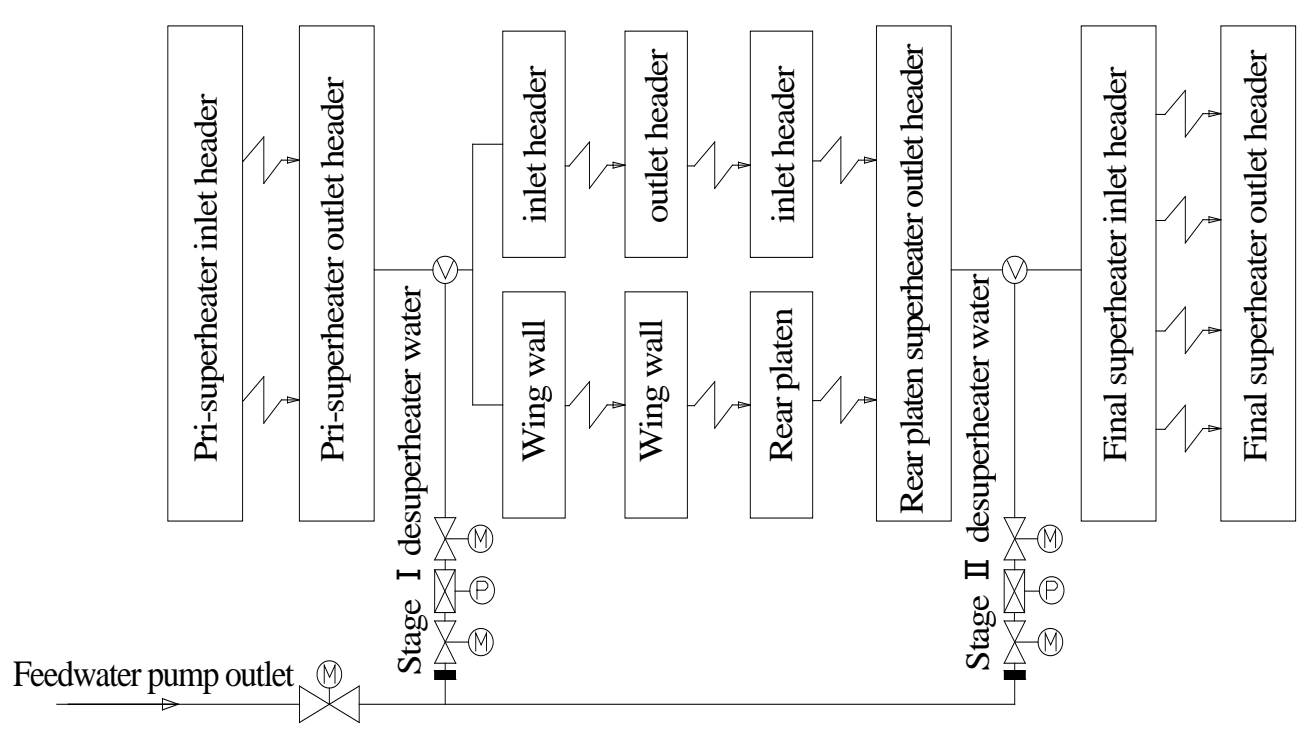

Fig. 1 Part of the main steam system diagram
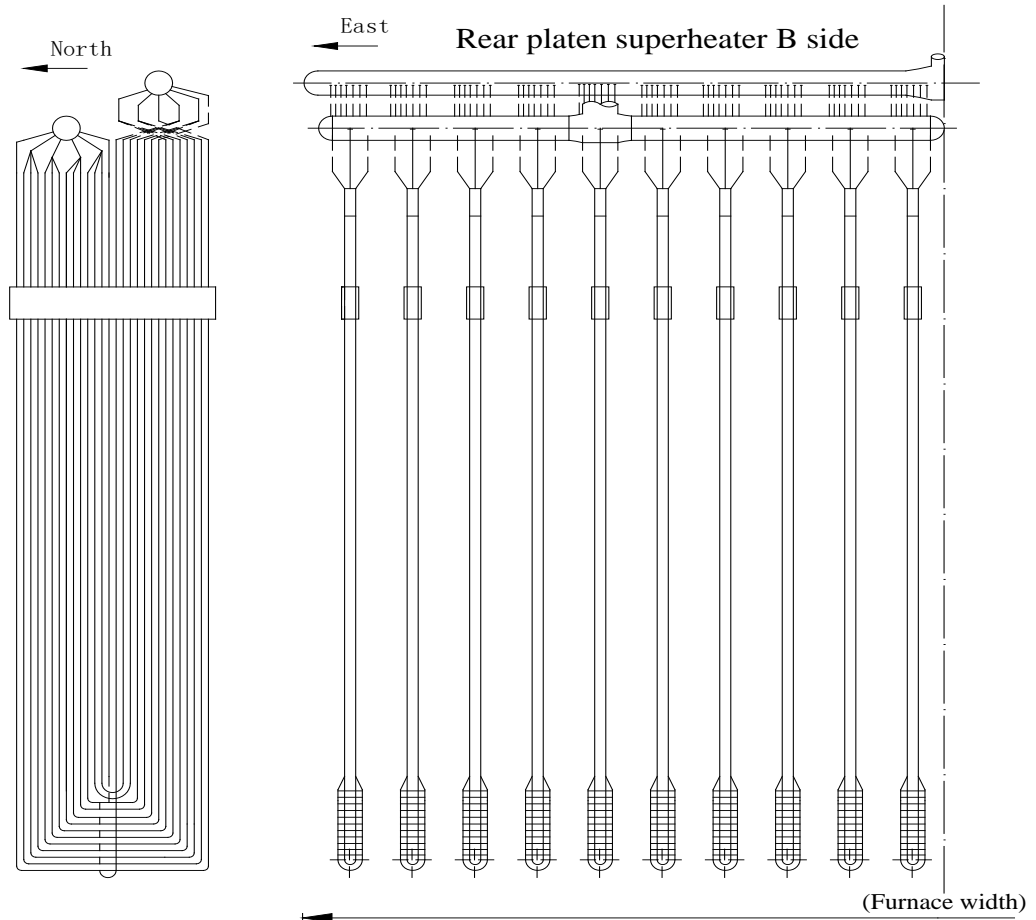

Fig. 2 Layout diagram of the rear panel superheater's single side and B-side tube panel

In February 2016, a water plug tube explosion in the rear panel superheater occurred. There were three water plug tube explosions of the final superheater in the previous 3 years, two of which were caused by the water plug. It's necessary to analyze the cause of the water plug tube explosions and put forward preventive measures.

\section{Analysis of the causes of tube explosion}

Causes investigation. On February 14, 2016, it was found that the vibration of No.1 bearing was large after the first ignition of Unit 4. After processing, it was ignited at 12:30. The unit was paralleled at 14:45 and operated with 220MW load. At 21:00, the furnace pressure suddenly increased to $376 \mathrm{~Pa}$ and the feed water flow also increased. It was found that there was a leak noise in 
the B-side furnace boiler of the No. 4 boiler $46 \mathrm{~m}$. It was judged that the pressure-containing parts in the furnace exploded.

After stopping the boiler and checking, it was found that the No. 12 tube in the north of the second panel of B side of the real panel superheater exploded and the explosion shape was shown in Figure 3. The explosion mouth was $1.5 \mathrm{~m}$ from the elbow with a shape of the trumpet. The edge was sharp and the diameter of the tube near the mouth was increased. The surface was gray-black. The shape of the mouth is consistent with the characteristics of the explosion mouth shape caused by the short-time overheating, so the initial reason was determined to be the short-term overheating.

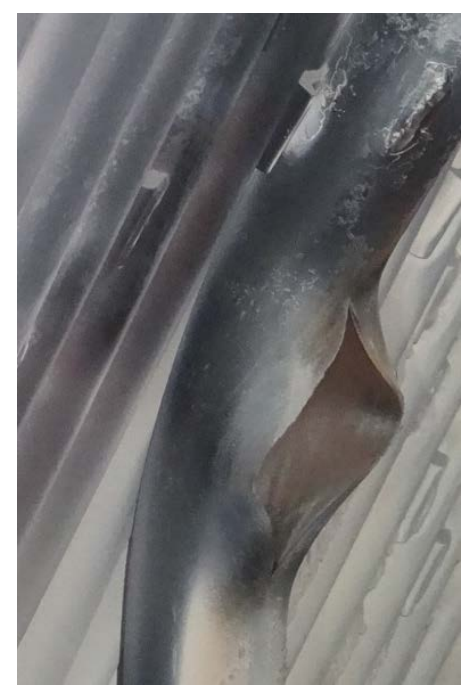

Fig. 3 Explosion shape

No oxide skin or other foreign matter was found after the further inspection of the rear panel tube. There was a lot of liquid water in the tube when the damaged tube was cut. The specific situation was as shown in Table 1, Table 2 (the water height in the tube is its distance from the elbow). The layout of the B-side rear panel superheater was shown in Figure 2. The heating tubes were named from north to south as the first, the second, .... The No. 1 elbows in the north of No. 41, 42, 43 rows in the east of the final superheater were found to have no water stored, and the wall thickness was normal.

Table 1 Water storage conditions in B-side rear panel superheater

\begin{tabular}{ccc}
\hline Panel & Pipe & Water storage height $/ \mathrm{m}$ \\
\hline East 1 & 4 & 1.2 \\
East 1 & 5 & 1.2 \\
East 1 & 6 & 1.2 \\
East 2 & 5 & 1.6 \\
East 2 & 3 & 1.5 \\
East 2 & 4 & 1.3 \\
East 2 & 7 & 1.8 \\
East 3 & 1 & $>1.7$ \\
East 3 & 3 & $>1.7$ \\
East 3 & 11 & 2.0 \\
East 4 & 1 & $>1.7$ \\
East 4 & 3 & $>1.7$ \\
East 5 & 1 & 0.6 \\
East 5 & 3 & 0.8 \\
East 6 & 1 & 0.2 \\
East 6 & 3 & 0.4 \\
\hline
\end{tabular}


Table 2 Water storage conditions in A-side rear panel superheater

\begin{tabular}{ccc}
\hline Numble & Scheme 1 & Scheme 2 \\
\hline Panel & Pipe & Water storage height $/ \mathrm{m}$ \\
West 1 & Holding tube & 0.50 \\
West 2 & Holding tube & 0.35 \\
West 3 & Holding tube & 0.30 \\
West 4 & Holding tube & 0.28
\end{tabular}

From Table 1 and Table 2, it can be known that there was more water in the Panel 4 (East 1-4) near the explosion mouth, with the highest being nearly $2.0 \mathrm{~m}$. There was a small amount of water in the holding tube in the west side and there was no water in the elbow. Under normal circumstances, when the unit was shut down, there will be some condensed water in the platen superheater, but it is abnormal that there is such a large amount of condensed water. It can be seen from Figure 1 that, the rear panel superheater is not directly connected with the primary desuperheating water, so the primary desuperheating water cannot reach the rear panel by going across the platen superheater. The secondary desuperheating water can only be leaked to the final superheater. So the possibility that the leakage of the desuperheating water causes the accumulated water can be excluded.

Combined with the operation, it can be seen that, the unit has an emergency stop at 11:40 due to the large bearing vibration. At 12:30, it was reignited. At 22: 10, the furnace pressure alarmed and the tube exploded. It took 50 min from the emergency stop due to the vibration in the first ignition to the second ignition. During the emergency stop, there was a large amount of condensed water in the superheater tube. During the second ignition of the unit, the drain valve at the inlet and outlet header didn't discharge the condensed water in the rear panel superheater tube, resulting in the water plug. In the heating process, the water plug cannot be completely discharged, resulting in the tube explosion.

\section{Summary}

Through the several water plug tube explosions in this plant, it can be known that it is necessary to open the atmospheric relief valve and the drain valve of the superheater during the starting and stopping of the boiler in time. Drain the condensed water in the superheater so as to avoid the water plug tube explosions. In addition, the leakage of the desuperheating water is also an important cause to the water plug tube explosion of the superheater. When the superheater behind the desuperheating water valve explodes due to the water plug, it's essential to check whether the desuperheating water control valve is tight or not first.

\section{References}

[1] Mei Wei. Boiler Water Wall Explosion Tube Mechanism and Preventive Measures [D]. Beijing: North China Electric Power University, 2011.

[2] Gao Qian, Liu Naijiang, Liu Yin, et al. Case Study on Fault Diagnosis of Pulverized Coal Boiler Tube Explosion, J. Commun. 9(2014) 70-73.

[3] Gao Hui. Analysis and Preventive Measures of Boiler High-temperature Superheater Tube Explosion, J. Commun. 11(2009) 84-86.

[4] Xiao Sanxia, Xiao Boqi. Analysis on Boiler High-temperature Superheater Tube Explosion in a Power Plant, J. Commun. 27(2012) 163-164,168.

[5] Xiao Zhemin. Formation and Elimination of Boiler Convection Superheater Water Plug, J. North Commun. 4 (2001) 55-58. 